\title{
Cardiac amyloidosis and aortic stenosis: Great masquerader back again!
}

\author{
Sertaç Çiçek, MD
}

From the Department of Cardiovascular Surgery, Mayo Clinic, Rochester, Minn

Disclosures: Author has nothing to disclose with regard to commercial support.

Received for publication Jan 23, 2018; accepted for publication Jan 31, 2018; available ahead of print March 2 , 2018 .

Address for reprints: Sertaç Çiçek, MD, Department of Cardiovascular Surgery, Mayo Clinic, 200 First St SW, Rochester, MN 55905 (E-mail: cicek.m@mayo.edu)

J Thorac Cardiovasc Surg 2018;156:104-5

$0022-5223 / \$ 36.00$

Copyright (c) 2018 by The American Association for Thoracic Surgery

https://doi.org/10.1016/j.jtcvs.2018.01.080

Cardiac involvement is a common finding in patients with all types of systemic amyloidosis, including hereditary and age-related (senile) forms, and it often goes unrecognized. ${ }^{1,2}$ The presence of cardiac amyloidosis carries a poor prognosis; patients with the hereditary type have been reported to have a median survival of 24 to 66 months, and patients with age-related amyloidosis (wild-type transthyretin) have been reported to have a median survival of 75 months. ${ }^{3}$

Degenerative aortic stenosis and age-related amyloidosis share common demographic and clinical characteristics. Cardiac amyloidosis could cause excessive cardiac remodeling or a restrictive physiology that might mimic paradoxic low-flow, low-gradient aortic stenosis (AS), which may easily be missed, making the clinical management challenging. Both surgical aortic valve replacement and transcatheter aortic valve replacement (TAVR) provide excellent outcomes in elderly patients with isolated AS. It is well known, however, that some patients benefit less than others from any heart valve replacement procedure, whether transcatheter or surgical. Previous reports have suggested the potential negative impact of transthyretin amyloidosis in patients with severe AS. At 2-year followup among 146 patients who underwent surgical aortic valve replacement, the presence of amyloidosis was associated with death, with a hazard ratio of $9.5 .^{4}$ In a retrospective study of 171 patients with transthyretin amyloidosis and without AS, mortality was the same irrespective of aortic valve replacement, suggesting that transthyretin amyloidosis may have a deleterious contribution to outcomes. Whether amyloidosis affects mortality synergistically with severe AS or whether it is the primary driver of poor outcomes in patients needs further exploration in large cohorts. Nietlispach and associates ${ }^{6}$ reported that myocardial amyloidosis was present in nearly one-third of all autopsy cases after TAVR and might have contributed to death from progressive heart failure. ${ }^{6}$

In this issue of the Journal, Java and colleagues ${ }^{7}$ present the results of a series of 16 patients with confirmed

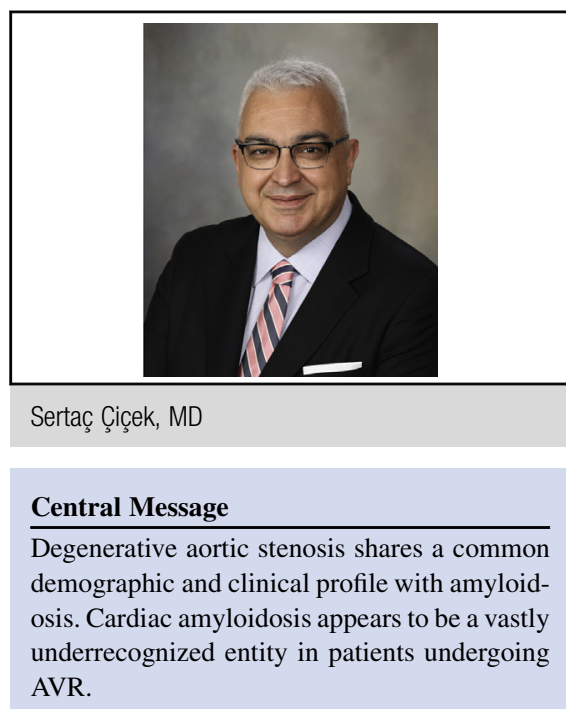

See Article page 98

amyloidosis, undergoing surgical AVR $(\mathrm{n}=11)$ or transfemoral TAVR $(n=5)$ to treat AS. Their results show excellent perioperative outcomes. Although follow-up was rather heterogeneous, 4 patients died later than 1 year after surgery. Java and colleagues ${ }^{7}$ suggest that aortic valve replacement, either surgical or TAVR, in patients with cardiac amyloidosis is a safe procedure and should be considered for all patients who are deemed good candidates. They provide little detail about the degree of cardiac infiltration and measures of cardiac involvement, whether measured by echocardiography, magnetic resonance imaging, or positron emission tomography. It is well known that these patients can present with different degrees of involvement with amyloid infiltration, which might significantly alter the prognosis.

As mentioned by Java and colleagues ${ }^{7}$ in their discussion of limitations, there is an inherent selection and referral bias in zooming in on the 16 patients who were referred from among more than 2600 patients in their amyloidosis clinic. The effect of aortic valve replacement on outcomes in patients with amyloidosis and AS would be better delineated by also looking at the natural history of patients who did not undergo aortic valve replacement. The similar mortality observed by Sperry and colleagues ${ }^{5}$ in patients with amyloidosis with or without AS justifies the search for less invasive treatment options, of which TAVR is one. 
The presence of concomitant cardiac amyloidosis is an important and probably vastly underrecognized entity in elderly patients undergoing aortic valve replacement. Most recently, Scully and colleagues ${ }^{8}$ reported that $13.9 \%$ recipients of TAVR have occult cardiac amyloidosis. The question of recognizing it and determining the early and midterm outcomes of patients after surgery is therefore of extreme importance for appropriate risk stratification and to choose the appropriate therapy. It is clear that operative decision making is complex, and the decision to operate should depend on the type of amyloidosis, the severity of the cardiac involvement, and the overall prognosis. Current data support the contention that aortic valve replacement can be performed with low operative risk and provides excellent symptom relief, but the data are insufficient to inform us regarding whether aortic valve replacement will improve long-term survival.

\section{References}

1. Kristen AV, Schnabel PA, Winter B, Helmke BM, Longerich T, Hardt S, et al. High prevalence of amyloid in 150 surgically removed heart valves - a comparison of histological and clinical data reveals a correlation to atheroinflammatory conditions. Cardiovasc Pathol. 2010;19:228-35.

2. Shah KB, Inoue Y, Mehra MR. Amyloidosis and the heart: a comprehensive review. Arch Intern Med. 2006;166:1805-13.

3. Mankad AK, Seray I, Shah KB. Light-chain cardiac amyloidosis. Curr Probl Cancer. 2017;41:144-56.

4. Treibel TA, Fontana M, Gilberston JA, Castelletti S, White SK, Scully PR, et al Occult transthyretin cardiac amyloid in severe calcific aortic stenosis: prevalence and prognosis in patients undergoing surgical aortic valve replacement. Circ Cardiovasc Imaging. 2016;9:https://doi.org/10.1161/CIRCIMAGING.116.005066.

5. Sperry BW, Jones BM, Vranian MN, Hanna M, Jaber WA. Recognizing transthyretin cardiac amyloidosis in patients with aortic stenosis: impact on prognosis. JACC Cardiovasc Imaging. 2016;9:904-6.

6. Nietlispach F, Webb JG, Ye J, Cheung A, Lichtenstein SV, Carere RG, et al. Pathology of transcatheter valve therapy. JACC Cardiovasc Interv. 2012;5:582-90.

7. Java AP, Greason KL, Dispenzieri A, Grogan M, King KS, Maleszewski JJ, et al Aortic valve replacement in patients with amyloidosis. J Thorac Cardiovasc Surg. 2018;156:98-103

8. Scully PR, Treibel TA, Fontana M, Lloyd G, Mullen M, Pugliese F, et al. Prevalence of cardiac amyloidosis in patients referred for transcatheter aortic valve replacement. J Am Coll Cardiol. 2018;71:463-4. 